\title{
Ergonomics as a Social Component of Sustainable Lot-sizing: A Review
}

\author{
Sezen Korkulu, Krisztián Bóna ${ }^{1}$ \\ ${ }^{1}$ Department of Material Handling and Logistics Systems, Faculty of Transportation Engineering and Vehicle Engineering, \\ Budapest University of Technology and Economics, H-1111 Budapest, Bertalan L. u. 7-9. Building L, Hungary \\ * Corresponding author, e-mail: sezen.korkulu@logisztika.bme.hu
}

Received: 25 March 2018, Accepted: 25 April 2018, Published online: 28 January 2019

\begin{abstract}
Lot-sizing has an increased attention in recent years. In the area of production planning and control, this trend has given rise to the development of lot-sizing models that considers sustainability issues besides the optimization of total operational cost. The study is based on tertiary study that is ensured to analyze the total work have been published. The research was conducted by the definition of appropriate keywords for understanding sustainability issues and ergonomics as a social component in lot-sizing. The paper at hand attempts to understand the development of sustainability issues in lot-sizing and ergonomics as a social component in lotsizing. We observe that studies focusing on all three dimensions of sustainability are comparatively scarce. However, only a few of the studies have been covered the social sustainability aspect. It is observed that studies addressing ergonomics issues are scarce, and more focus is required on the social sustainability impacts along the supply chain and lot-sizing. Most of ergonomic assessment covered relaxation allowance and energy expenditure rate, OWAS, NIOSH and another consideration about ergonomic lot-sizing is the motion types investigated by authors which were picking, storing as a lifting and carrying motions and did not covered pushing, pulling, bending and other hand motions which have positive relationship with work related musculoskeletal disorders. Finally, we propose future directions to extend research on the ergonomics in lot-sizing.
\end{abstract}

Keywords

ergonomics, intralogistics, literature review, lot-sizing, social sustainability

\section{Introduction}

The supply chain management term was first coined by Keith Oliver in 1982. However, the concept of a supply chain management has been used to describe the planning and control of materials, information flows and the logistic activities within companies (Cooper et al., 1997). In process of time, research focus of supply chain management has broadened (Burgess et al., 2006). Primarily, supply chain management focused on material flow. Recently, research on supply chain management emphasizes the other aspects, such as supply chain risk management (Giannakis and Papadopoulos, 2016), supply chain performance measures (Hassini et al., 2012), green supply chain network design integration (Rezaee et al., 2017) and sustainability (Wolf, 2011).

According to Ahi and Searcy (2013), sustainable supply chain can be defined as; the creation of unified supply chains through intentional integration of economic, environmental, and social considerations with business systems designed to efficiently and effectively manage the material, information, and capital flows connected with the procurement, production, and distribution of products or services and further the profitability, competitiveness, and resilience of the organization over the short and long-term. However, the social sustainability issues did not receive much attention both in supply chain management and lot-sizing. Absi et al. (2013) investigated the lot-sizing with carbon emission constraints. Fichtinger et al. (2015) assessed the environmental impacts of inventory and warehouse management. An examination of the relationship between operational practices and performance among early adopters of green supply chain management practices in Chinese manufacturing enterprises have been done by Zhu and Sarkis (2004). In their study, they used moderated hierarchical regression analysis and evaluated the general relationships between green supply chain management practice and performance. Zailani et al. (2012) have investigated the extension of implementation of 
sustainable supply chain practices as a survey in Malaysia. In their study, they applied factor analysis which the survey data resulted in four categories of outcomes (environmental, social, economic and operational). According to their results; sustainability in supply chain has a positive effect on environmental, social and economic outcomes. This paper aims to analyze sustainability directions in lot-sizing with undertaking an extensive literature review and identifying history of lot-sizing and practices in terms of utilization for future research directions and studies the scope of ergonomics as a social sustainability component and understanding the effects in intralogistics systems. Therefore, the major objectives of this study are to:

1. understand the development of sustainability issues in lot-sizing,

2. study the progress of ergonomics research in lot-sizing literature in recent years across various themes of study,

3. study the future scope of lot-sizing within ergonomics.

The next section has been presented the detail of the methodology adopted to carry the entire study. Section 3 reviews literature on history of lot-sizing and sustainability issues in lot-sizing and provides an understanding of the existing literature of work related musculoskeletal disorders and ergonomics in lot-sizing. Section 4 examines the results outlined in Section 3. Finally, the conclusions of the entire study, including the future scope of ergonomics issues in lot-sizing research, have been outlined in Section 5.

\section{Methodology}

This article reviews research on sustainability issues in lot-sizing and ergonomics in lot-sizing and identifies several topics that offer opportunities for future research. The present study is based on the methodology of tertiary study that is ensured to analyze the total work have been published and tertiary studies are used to investigate core themes that were studied in a particular research area and this methodology applied in this study based on work of Glock et al. (2014). The literature research structure was conducted by a process model proposed by Mayring (2000) and contains following steps: the definition of appropriate keywords, research of the appropriate keywords in databases, collection of the material and selection of the paper for ensuring reliability. Literature resources were collected for understanding sustainability issues and ergonomics as a social component in lot-sizing. Keywords were defined to recognize the relevant works in the literature which helped to focus on the correct theme. The keywords used were EOQ, ergonomics, EPQ, relaxation allowance, energy expenditure, inventory management, lot-sizing and social sustainability. In this study, only articles published in peer reviewed journals using English language were selected.

\section{Results of literature research}

\subsection{Lot sizing}

Lot size refers to the quantity of an item ordered for delivery on a specific date or manufactured in a single production run. In other words, lot size basically refers to the total quantity of a product ordered for manufacturing. In this section a lot-sizing literature summary is given: starting from the history of lot-sizing, the sustainability of lot-sizing.

\subsubsection{History of lot-sizing}

The economic order quantity (EOQ) model was first coined by Ford Whitman Harris (Andriolo et al., 2014). In his study, he proposed the formulation of economic order quantity under the assumption of a continuous constant rate for demand and the need to balance intangible inventory costs against tangible costs for ordering. According to Harris (1913) formulation of EOQ model:

$M$ : equals the number of units used per month

$C$ : the unit cost, without considering the set up or getting ready expense

$S$ : equals the set up cost of an order

$T$ : the time required to make up and deliver to the storage room an order

$I$ : equals the unit charge for interest and depreciation on stock.

$X$ : optimal order, lot size, which is most economical.

$Y$ : total cost per unit.

According to Eq. (1) and Eq. (2), the whole cost of a unit $(Y)$ and economical lot size $(X)$ is equal to (Harris, 1913):

$Y=1 / 240 M(C X+S)+S / X+C$

$X=\sqrt{240 * M * S / C}$.

In the literature, different alternative methods to derive the economic order quantity were presented. EOQ model was extended for allowing backorders by Grubbström and Erdem (1999). After that, the model was extended with shortages by Cárdenas-Barrón (2001). In this study, the author was extended the study of Grubbström and Erdem (1999) model with the shortage in the case of one shortage cost per unit and time unit. In 2002, Yang and 
Wee (2002) derived the model which considering the integrated vendor-buyer inventory system without derivatives. After that, $\mathrm{Wu}$ and Ouyang (2003) extended the study of Yang and Wee (2002) by integration of shortage to the single vendor single buyer inventory system. In their study, they have been proposed algebraic procedure for finding optimal values of buyer's lot size per order, maximum shortage level for buyer, number of deliveries from the vendor to the buyer per cycle time.

\subsubsection{Sustainability in lot-sizing}

Sustainability has considerably grown an importance during the last few years. Therefore, there is an increasing concern in lot-sizing research on environmental and social sustainability issues. The single and multi-stage lot-sizing models merged with carbon emission constraint for cost minimization have been done by Benjaafar et al. (2013). In their study, they examined different policies such as strict carbon cap, a tax on the amount of emissions, the cap and trade system. In 2012, a sustainable economic production quantity model was developed by Glock et al. (2012). In their study, they created a mathematical model that considers the environmental and economic dimensions of sustainability which incorporates controlling scrap and emissions on environmental quality index in their lot-sizing model and the model was investigated in a simple two-level supply chain. Their study was shown that by controlling scrap and emission, the manufacturer and the supplier could attract more customers and increase their profits. Wahab et al. (2011) developed an economic order quantity model for two level supply chain both domestic and international which considers $\mathrm{CO}_{2}$ emissions. In their study, they considered two types of emission, first one is fixed emissions which are related the fuel efficiency of vehicle used and other factors which are related to the system. The other emission was variable emissions which are depends on the lot size. They merged emissions to the model as an emission costs and figured out the total expected cost per unit time for the integrated green supply chain.

\subsection{Ergonomics}

According to International Ergonomics Association; "ergonomics" is derivation of ergon(work) and nomos(laws) Greek words which represents the scientific discipline concerned with the understanding of interactions among humans and other elements of a system.

Recently, the role and importance of ergonomics in production systems and effects on increasing productivity have been understood by the others. Even tough automated production systems are most widely used, there are still many jobs that must include the human factor. Therefore, human factor will still maintain their position in the future, productivity and sustainability of human factor are important in production systems.

In this section an ergonomics literature summary is given: starting from the work related musculoskeletal disorders, the ergonomics in lot-sizing.

\subsubsection{Work related musculoskeletal disorders}

Musculoskeletal disorders are injuries or disorders of the muscles, nerves, tendons, joints, peripheral nerves, supporting blood vessels and do not include disorders caused by slips, falls, or motor or similar incidents. According to Punnett and Wegman (2004), musculoskeletal disorders include sprains, back pain, hurt back, carpal tunnel syndrome; hernia; and musculoskeletal system and connective tissue diseases and disorders when the event or exposure leading to the case is bodily reaction (bending, climbing, crawling, reaching), or repetitive motion. Work related musculoskeletal disorders are related to high cost for the employers such as lost productivity, disability and compensation cost. According to European Agency for Safety and Health at Work last report (EU-OSHA, 2010), $38.1 \%$ of EU workers have musculoskeletal diseases and most common and important musculoskeletal disorders risk factor is repetitive work. In 2015, the Bureau of Labor Statistics (BLS, 2015) reported 31 percent of total cases of musculoskeletal diseases in the U.S.

According to National Research Council and Institute of Medicine (2001) and Punnett and Wegman (2004), null and positive associations of work-related risk factors and the occurrence of back disorders.

Upper extremity disorder and back disorder occurrencies have positive relationship with work related risks, which are given in Table 1 and Table 2. Therefore, it has been proven that musculoskeletal disorders mainly occur with work related risks. As given in Table 1 and Table 2, attributable fraction is an estimate of the proportion of disease that would be reduced in the exposed population.

\subsubsection{Ergonomics in lot-sizing}

Recent studies have been shown the interest on sustainability issues in lot-sizing models. In the literature, studies on sustainability issues mostly related to economic and environmental dimensions of sustainability. As described in detailed on the title of sustainability in lot-sizing, Glock 
Table 1 Attributable fraction and null and positive association of work related physical risk factors for back disorders

\begin{tabular}{lccc}
\hline $\begin{array}{l}\text { Work related risk } \\
\text { factor }\end{array}$ & Null (n) & Positive (n) & $\begin{array}{l}\text { Attributable } \\
\text { Fraction (\%) }\end{array}$ \\
\hline $\begin{array}{l}\text { Manual material } \\
\text { handling }\end{array}$ & 4 & 24 & $11-66$ \\
$\begin{array}{l}\text { Frequent bending and } \\
\text { twisting }\end{array}$ & 2 & 15 & $19-57$ \\
$\begin{array}{l}\text { Heavy physical load } \\
\text { Static work posture }\end{array}$ & 0 & 8 & $31-58$ \\
Whole-body vibration & 1 & 3 & $14-32$ \\
\hline
\end{tabular}

Table 2 Attributable fraction and null and positive association of work related physical risk factors and the occurrence of upper extremity disorders

\begin{tabular}{lccc}
\hline $\begin{array}{l}\text { Work related } \\
\text { risk factor }\end{array}$ & Null (n) & Positive (n) & $\begin{array}{c}\text { Attributable } \\
\text { Fraction (\%) }\end{array}$ \\
\hline Repetition & 4 & 4 & $53-71$ \\
Force & 1 & 2 & 78 \\
Repetition and force & 0 & 2 & $88-93$ \\
Repetition and cold & 0 & 1 & 89 \\
Vibration & 6 & 26 & $44-95$ \\
\hline
\end{tabular}

et al. (2012) developed a sustainable economic production quantity model which considers the environmental and economic dimensions of sustainability which incorporates controlling scrap and emissions on environmental quality index in their lot-sizing model. Wahab et al. (2011) developed an economic order quantity model for two level supply chain both domestic and international which considers $\mathrm{CO}_{2}$ emissions which considered two types of emission, first one is fixed emissions which are related the fuel efficiency of vehicle used and other factors which are related to the system. They merged emissions to the model as an emission costs and figured out the total expected cost per unit time for the integrated green supply chain. Bouchery et al. (2012) considered the economic order quantity model as an sustainable order quantity model and also extended the sustainable order quantity model with multi-echelon and applied regulatory policies based on a carbon price and carbon cap. Their study was consisting of social and environmental sustainability aspects of inventory models that there were no suggestions about social impact. In their study, they considered environmental sustainability issues in inventory models and did not considered ergonomics. Aslan and Turkay (2013) extended the classical EOQ model with social and environmental sustainability aspects. In their study, they used the International Labour Organization working hours for the employees as a social metric. In their study, they revised the classical economic order quantity model with environmental and social sustainability criterias and also they did not consider ergonomics in their model.

After all searching a correlation between ergonomics and supply chain management, results were very poor according to seven papers were published which are given in Table 3.

Battini et al. (2011) analyed how ergonomics and assembly system design techniques are well related. Their study was the interaction between productivity and ergonomic evaluations in the human operations analysis which is a win-win approach and operational safety. They used OWAS for ergonomic assessment of work conditions and designing the assembly system. In their study, they considered the link between design of assembly system and ergonomics and they did not consider the quantitative assessment and they found that assembly design and ergonomics should be complimentary to each other to assess time efficiency and method analysis in modern industries. Battini et al. (2015b) developed for the first time in the literature a new measurement technique with consideration of energy expenditure equations (Garg et al., 1978) and rest allowance formulation (Rohmert, 1973). Their method allows calculating the energy expenditure for each task reducing the time spent to calculate the ergonomics measures and simplifying the ergonomics assessment of each assembly task. Equation (3) is the formulation developed by Battini et al. (2015b);

$E T(q)=\left(\left(T_{p}+T_{t}+T_{s}\right) *(1+R A) / A\right) * N_{t}$.

Where $\operatorname{ET}(q)$ is the total time spent for handling [s], $T_{p}$ is the total time required to pick the lot $q$ from the stock point [s], $T_{t}$ is the total travel time required to bring the

Table 3 Literature of ergonomics in sustainable supply chain management and the inventory model

\begin{tabular}{|c|c|c|c|}
\hline No & Authors & Year & Keywords \\
\hline 1 & Andriolo et al. & 2016 & $\begin{array}{l}\text { EOQ, social sustainability, } \\
\text { ergonomics }\end{array}$ \\
\hline 2 & Battini et al. & 2011 & $\begin{array}{l}\text { ergonomics productivity, } \\
\text { assembly system design }\end{array}$ \\
\hline 3 & Battini et al. & $2015 \mathrm{a}$ & $\begin{array}{l}\text { ergonomics, assembly system, } \\
\text { productivity }\end{array}$ \\
\hline 4 & Battini et al. & $2015 b$ & $\begin{array}{l}\text { EOQ, ergonomics, lot-sizing, } \\
\text { social sustainability }\end{array}$ \\
\hline 5 & Battini et al. & $2016 b$ & $\begin{array}{c}\text { ergonomics, rest allowances, } \\
\text { warehouse picking }\end{array}$ \\
\hline 6 & Battini et al. & $2016 a$ & $\begin{array}{c}\text { ergonomics, energy expenditure, } \\
\text { rest allowances }\end{array}$ \\
\hline 7 & Battini et al. & 2017 & $\begin{array}{l}\text { ergonomics, lot-sizing, rest } \\
\text { allowance, in-house logistics }\end{array}$ \\
\hline
\end{tabular}


lot $q[\mathrm{~s}], T_{s}$ is the total storage time that is needed to store the lot $q$ [s], $R A$ is rest allowance [kcal $/ \mathrm{min}], A$ is the availability of the operator $[\mathrm{kcal} / \mathrm{min}]$ and $N_{t}$ is total number of trips necessary to ship the total amount of items $Q$. They found that the improvement of ergonomics conditions has a relevant positive impact on the total cost of the system. In their study, they created the new model for lot-sizing which include human energy expenditure and rest allowance, but they did not consider maximum endurance time as an ergonomic variable.

Battini et al. (2016b) have considered assembly line balancing which includes energy expenditure rate. They developed a new multi-objective model for solving assembly line balancing problem which include also ergonomic aspect. In their model, they used Predetermined Motion Energy System (PMES) for estimation of energy expenditure rate and they created the mutli-objective model based on four different objective functions. Finally, they analyzed the relationship between time and energy values with Pareto frontiers. According to Eq. (4) and Eq. (5), the multi-objective assembly line balancing model is (Battini et al., 2016b):

$$
\begin{aligned}
& \min \{S X-T ; S X-E\} \\
& =\min \left\{\sqrt{\sum_{k=1}^{K}\left(c_{r}-\sum_{j \in B_{k}} x_{j k} \cdot t_{j}\right)^{2}} ; \sqrt{\sum_{k=1}^{K}\left(E_{r}-\sum_{j \in B_{k}} x_{j k} \cdot e_{j}\right)^{2}}\right\} \\
& \min \{M-M S T ; M-M S E\} \\
& =\min \left\{\begin{array}{l}
\max \left\{\sum_{j \in B_{k}} x_{j k} \cdot t_{j} \mid k=1 \ldots K\right\} ; \\
\max \left\{\sum_{j \in B_{k}} x_{j k} \cdot e_{j} \mid k=\ldots K\right\}
\end{array}\right\} .
\end{aligned}
$$

Where $S X-T$ is the Time Smoothness Index, $S X-E$ is the Energy Smoothness Index, $k$ is set of work station, $c_{r}$ is the maximum station time among all stations, $j$ is the task, $x_{j k}$ is a binary variable which is used to indicate the assignment, with 1 if task $j$ is assigned to station $k$ and 0 , otherwise and $t_{j}$ is task times, $E_{r}$ is the maximum energy expenditure among the stations, $e_{j}$ is energy expenditure of task $j, M-M S T$ is the Mini-Max Station Time, $M-M S E$ is the Mini-Max Station Energy. In their study, they created multi-objective model based on the Time Smoothness Index and Mini-Max Station Time and they converted these two functions into Mini-Max Station Energy and Energy Smoothness Index with energy expenditure rate and Predetermined Motion Energy Systems.
Andriolo et al. (2016), proposed another lot-sizing model that considers ergonomic aspects. They proposed a multiobjective optimization approach that calculates Paretooptimal solutions that minimize both cost and ergonomic risks and was assessed using a lifting index $(L I)$ and did not consider the rest allowance concept, but instead compared the cost objective and the ergonomic objective using Pareto frontiers. According to Eqs. (6)-(8), the in-house and in-bound equations are equal to (Andriolo et al., 2016):

$$
\begin{aligned}
& C_{\text {totlH }}(q)=D / q * c_{f p}+D * c_{v p}+D / q *\left(c_{h w}+c_{h e} * x\right) * t_{u} \\
& L I(q)=q * u w / R W L \\
& C_{\text {totIB }}(n)=c . D+K .\left(D / n * q^{*}\right)+\left(n * q^{*} / 2\right) . h . c
\end{aligned}
$$

Where $C_{\text {tottH }}$ is the total cost of inhouse lot-sizing, $D$ is the annual demand of the item, $q$ is the number of items per $S K U, c_{f p}$ is he unit fixed cost of packaging, $c_{v p}$ is the unit variable cost of packaging per item, $c_{h w}$ is the labor cost per hour, $c_{h e}$ is the equipment cost per hour, $t_{u}$ is the handling operation time per $S K U, x$ is equal to 0 or 1 depends on operations performed manually or not, $L I$ is the lifting index, $u w$ is the unit weight, $R W L$ is the recommended weight limit, $C_{\text {totIB }}$ is the total cost of in-bound lot sizing, $c$ is the unit purchase cost per item, $K$ is the fixed cost of placing one order, $n$ is the number of $S K U$ s per order and $h$ is the unit stock holding cost per $€$ per year.

Battini et al. (2015a) have been developed two different cost functions (basic system and other one the system with the employment of stand-by units) which are considers the human availability and the rest allowance to the ergonomics level for warehouse picking activities. The total expected cost functions are given in Eq. (9) and Eq. (10):

$$
\begin{aligned}
& T E C_{b s}=c_{h} \cdot h_{T} \cdot\left(1-A_{h}\right)+c_{h} \cdot h_{T} \cdot R A \cdot A_{h} \\
& T E C_{s b}=c_{h} \cdot h_{T} \cdot\left(1-A_{h}^{\prime}\right)+c_{h} \cdot h_{T} \cdot R A \cdot A_{h}+c_{h} \cdot h_{T} \cdot R A \cdot\left(A_{h}^{\prime}-A_{h}\right) \\
& +c_{h} \cdot h_{T} \cdot(1-Q) \cdot\left(A_{h}^{\prime}-A_{h}\right) .
\end{aligned}
$$

Where $T E C_{b s}$ is total expected cost for basic system, $c_{h}$ is the hourly production cost in $€ / h, h_{T}$ is the time period expressed in hours, $A_{h}$ is the real human availability, $R A$ is the rest allowance, $T E C_{s b}$ is the total expected cost for a system with stand by unit, $A_{h}^{\prime}$ is the human availability in presence of stand-by operator and $Q$ is the lower productivity of the stand-by operator with respect to the standard operator (expressed in percentage). As a result, they have been demonstrated that a system with stand-by units 
is generally preferable and less affected by the human availability and improvement of ergonomics conditions has a relevant positive impact on the total cost of the system.

In 2016, integrated assembly line balancing and parts feeding with incorporation ergonomic aspects formulated mixed-integer model was developed by Battini et al. (2016a) They improved ergonomic conditions with increasing task processing times by rest allowances formulas of Garg et al. (1978) and Price (1990) if the energy expenditure of workers exceeds the recommended limit. Where $T$ is a rest time [min] and $E$ is a energy expenditure rate [ $\mathrm{kcal} / \mathrm{min}]$. Their new mixed-integer model is given in Eq. (11);

$T=\left\{\begin{array}{cc}0.41 * E-0.76 * T & \text { if } E>4.2927 \\ T & \text { otherwise }\end{array}\right.$.

Battini et al. (2017), proposed another lot-sizing model which considers ergonomic aspects and authors proposed a new mathematical model that integrates ergonomic and economic aspects and used rest allowance and energy expenditure rate functions are for take account of recovery periods that help to maintain low levels of fatigue and ergonomic risks. Their new model lot size equation is given in Eq. (12);

$q^{*}=(2 d / s) *\left(1 / 2 t_{p s}\right) * 4.3-E_{t} / E_{p s}-4.3$.

Where $q^{*}$ is ergonomic lot size [pcs], $d$ is distance between stock point $[\mathrm{m}], s$ is constant travel speed $[\mathrm{m} / \mathrm{s}]$, $t_{p s}$ is unitary picking / storing time [s], $E_{t}$ is metabolic cost for transportation activity $[\mathrm{kcal} / \mathrm{min}]$ and $E_{p s}$ is metabolic cost for picking / storing activity [ $\mathrm{kcal} / \mathrm{min}]$.

\section{Discussion}

This paper has a two-fold contribution to the lot-sizing literature. First, this research extends the existing literature in sustainability issues in lot-sizing by a framework that is based on experts opinions. Second, it gathers the efforts of authors such as Battini et al. (2017), in sustainable lot sizing with ergonomics assessment, for offering alternative approach to future research. In the literature the results found with the keyword "EOQ, EPQ, inventory management, lot-sizing" are commonly in environmental and economic sustainability of the system due to the common and established interest of these parameters in the industrial system. Conversely, the results from the literature research found seven on "ergonomics, relaxation allowance, energy expenditure, inventory management, lot-sizing" as a social sustainability component.

Our study has implications for social sustainability issues in lot-sizing in terms of ergonomics assessments that should pay attention in order to optimization of lot sizing process and intralogistics systems. Especially, this study underlines role of ergonomics in order to improve inventory management process in terms of social sustainability. The results of Battini et al. (2011), Battini et al. (2015a), Battini et al. (2015b), Battini et al. (2016a), Battini et al. (2016b), Battini et al. (2017) and Andriolo et al. (2016) show that ergonomic improvements in intralogistics systems will lead also economical sustainability. Therefore, these particular improvements in intralogistics systems will enable supply chains and organizations become more both environmentally friendly and economically stable.

\section{Conclusion}

Sustainable supply chain management has an increased attention in recent years. In the area of production planning and control, this trend has given rise to the development of lot-sizing models that consider sustainability issues besides the optimization of total operational cost. The developed and examined models from authors were starting point for ergonomics as a social sustainability component in lot-sizing and inventory management. Most of ergonomic assessment covered relaxation allowance and energy expenditure rate, OWAS, NIOSH and did not covered the maximum endurance time for better ergonomic assessment. Another consideration about ergonomic lot-sizing is the motion type investigated by authors. They examined picking, storing as a lifting and carrying motions but they did not investigated pushing, pulling, bending and other hand motions which have positive relationship with work related musculoskeletal disorders. Therefore, further research is needed for investigation of maximum endurance time in lot-sizing and other motions which cause work related musculoskeletal disorders.

Ahi, P., Searcy, C. (2013) "A comparative literature analysis of definitions for green and sustainable supply chain management", Journal of Cleaner Production, 52, pp. 329-341. https://doi.org/10.1016/j.jclepro.2013.02.018

\section{References}

Absi, N., Dauzère-Pérès, S., Kedad-Sidhoum, S., Penz, B., Rapine, C. (2013) "Lot sizing with carbon emission constraints", European Journal of Operational Research, 227(1), pp. 55-61. https://doi.org/10.1016/j.ejor.2012.11.044 
Andriolo, A., Battini, D., Grubbström, R. W., Persona, A., Sgarbossa, F. (2014) "A century of evolution from Harris's basic lot size model: Survey and research agenda", International Journal of Production Economics, 155, pp. 16-38. https://doi.org/10.1016/j.ijpe.2014.01.013

Andriolo, A., Battini, D., Persona, A., Sgarbossa, F. (2016) "A new bi-objective approach for including ergonomic principles into EOQ model", International Journal of Production Research, 54(9), pp. 2610-2627.

https://doi.org/10.1080/00207543.2015.1113324

Arslan, M. C., Turkay, M. (2013) "EOQ Revisited with Sustainability Considerations", Foundations of Computing and Decision Sciences, 38(4), pp. 223-249. https://oi.org/10.2478/fcds-2013-0011

Battini, D., Faccio, M., Persona, A., Sgarbossa, F. (2011) "New methodological framework to improve productivity and ergonomics in assembly system design", International Journal of Industrial Ergonomics, 41(1), pp. 30-42 https://doi.org/10.1016/j.ergon.2010.12.001

Battini, D., Calzavara, M., Persona, A., Sgarbossa, F. (2015a) "Linking human availability and ergonomics parameters in order-picking systems", IFAC-PapersOnLine, 48(3), pp. 345-350. https://doi.org/10.1016/j.ifacol.2015.06.105

Battini, D., Glock, C. H., Grosse, E. H., Persona, A., Sgarbossa, F. (2015b) "Ergo-Lot-Sizing: Considering Ergonomics in Lot-Sizing Decisions", IFAC-PapersOnline, 48(3), pp. 326-331. https://doi.org/10.1016/j.ifacol.2015.06.102

Battini, D., Calzavara, M., Otto, A., Sgarbossa, F. (2016a) "The Integrated Assembly Line Balancing and Parts Feeding Problem with Ergonomics Considerations", IFAC-PapersOnLine, 49(12), pp. 191-196. https://doi.org/10.1016/j.ifacol.2016.07.594

Battini, D., Delorme, X., Dolgui, A., Persona, A., Sgarbossa, F. (2016b) "Ergonomics in assembly line balancing based on energy expenditure: a multi-objective model", International Journal of Production Research, 54(3), pp. 824-845. https://doi.org/10.1080/00207543.2015.1074299

Battini, D., Glock, C. H., Grosse, E. H., Persona, A., Sgarbossa, F. (2017) "Ergo-lot-sizing: An approach to integrate ergonomic and economic objectives in manual materials handling", International Journal of Production Economics, 185, pp. 230-239. https://doi.org/10.1016/j.ijpe.2017.01.010

Benjaafar, S., Li, Y., Daskin, M. (2013) "Carbon Footprint and the Management of Supply Chains: Insights From Simple Models", IEEE Transactions on Automation Science and Engineering, 10(1), pp. $99-116$. https://doi.org/10.1109/TASE.2012.2203304

BLS (Bureau of Labor Statistics) (2015) "Nonfatal Occupational Injuries And Illnesses Requiring Days Away From Work", [online] Available at: https://www.bls.gov/news.release/pdf/osh2.pdf [Accessed: 23rd November 2017]

Bouchery, Y., Ghaffari, A., Jemai, Z., Dallery, Y. (2012) "Including sustainability criteria into inventory models", European Journal of Operational Research, 222(2), pp. 229-240. https://doi.org/10.1016/j.ejor.2012.05.004
Burgess, K., Singh, P. J., Koroglu, R. (2006) "Supply chain management: a structured literature review and implications for future research", International Journal of Operations \& Production Management, 26(7), pp. 703-729. https://doi.org/10.1108/01443570610672202

Cárdenas-Barrón, L. E. (2001) "The economic production quantity (EPQ) with shortage derived algebraically", International Journal of Production Economics, 70(3), pp. 289-292. https://doi.org/10.1016/S0925-5273(00)00068-2

Cooper, M. C., Lambert, D. M., Pagh, J. D. (1997) "Supply Chain Management: More Than a New Name for Logistics", The International Journal of Logistics Management, 8(1), pp. 1-14. https://doi.org/10.1108/09574099710805556

EU-OSHA (European Agency for Safety and Health at Work) (2010) "European Risk Observatory Report", [online] Available at: file://C:/Users/User/Downloads/4fe9b5a982cbd_TERO09009EC. pdf [Accessed: 31st October 2017]

Fichtinger, J., Ries, J. M., Grosse, E. H., Baker, P. (2015) "Assessing the environmental impact of integrated inventory and warehouse management", International Journal of Production Econonmics, 170(C), pp. 717-729. https://doi.org/10.1016/j.ijpe.2015.06.025

Garg, A., Chaffin, D. B., Herrin, G. D. (1978) "Prediction of metabolic rates for manual materials handling jobs", The American Industrial Hygiene Association Journal, 39(8), pp. 661-674. https://doi.org/10.1080/0002889778507831

Giannakis, M., Papadopoulos, T. (2016) "Supply chain sustainability: A risk management approach", International Journal of Production Economics, 171(4), pp. 455-470. https://doi.org/10.1016/j.ijpe.2015.06.032

Glock, C. H., Jaber, M. Y., Searcy, C. (2012) "Sustainability strategies in an EPQ model with price- and quality-sensitive demand", The International Journal of Logistics Management, 23(3), pp. 340-359. https://doi.org/10.1108/09574091211289219

Glock, C. H., Grosse, E. H., Ries, J. M. (2014) "The lot sizing problem: A tertiary study", International Journal of Production Economics, 155, pp. 39-51. https://doi.org/10.1016/j.ijpe.2013.12.009

Grubbström, R. W., Erdem, A. (1999) "The EOQ with backlogging derived without derivatives", International Journal of Production Economics, 59(1-3), pp. 529-530. https://doi.org/10.1016/S0925-5273(98)00015-2

Harris, F. W. (1913) "How many parts to make at once", Factory, The Magazine of Management, 10(2), pp. 135-136. [Reprinted in Operations Research, 1990, 38(6), pp. 947-950.] https://doi.org/10.1287/opre.38.6.947

Hassini, E., Surti, C., Searcy, C. (2012) "A literature review and a case study of sustainable supply chains with a focus on metrics", International Journal of Production Economics, 140(1), pp. 69-82. https://doi.org/10.1016/j.ijpe.2012.01.042

Mayring, P. (2000) "Qualitative Content Analysis", Forum: Qualitative Sozialforschung / Forum: Qualitative Social Research, 1(2), Art. 20. https://doi.org/10.17169/fqs-1.2.1089 
National Research Council, Institute of Medicine (2001) "Musculoskeletal Disorders and the Workplace: Low Back and Upper Extremities", National Academy Press, Washington, DC, USA. [online] Available at: https://www.ncbi.nlm.nih.gov/books/NBK222440/ pdf/Bookshelf_NBK222440.pdf [Accessed: 10th November 2017]

Price, A. D. (1990) "Calculating relaxation allowances for construction operatives - Part 1: Metabolic cost", Applied Ergonomics, 21(4), pp. 311-317.

https://doi.org/10.1016/0003-6870(90)90202-9

Punnett, L., Wegman, D. H. (2004) "Work-related musculoskeletal disorders: the epidemiologic evidence and the debate", Journal of Electromyography and Kinesiology, 14(1), pp. 13-23. https://doi.org/10.1016/j.jelekin.2003.09.015

Rezaee, A., Dehghanian, F., Fahimnia, B., Beamon, B. (2017) "Green supply chain network design with stochastic demand and carbon price", Annals of Operations Research, 250(2), pp. 463-485. https://doi.org/10.1007/s10479-015-1936-z

Rohmert, W. (1973) "Problems of determination of rest allowances Part 2: Determining rest allowances in different human tasks", Applied Ergonomics, 4(3), pp. 158-162. https://doi.org/10.1016/0003-6870(73)90166-X

Wahab, M. I. M., Mamun, S. M. H., Ongkunaruk, P. (2011) "EOQ models for a coordinated two-level international supply chain considering imperfect items and environmental impact", International Journal of Production Economics, 134(1), pp. 151-158. https://doi.org/10.1016/j.ijpe.2011.06.008
Wolf, J. (2011) "Sustainable Supply Chain Management Integration: A Qualitative Analysis of the German Manufacturing Industry", Journal of Business Ethics, 102(2), pp. 221-235. https://doi.org/10.1007/s10551-011-0806-0

Wu, K. S., Ouyang, L. Y. (2003) "An integrated single-vendor single-buyer inventory system with shortage derived algebraically", Production Planning and Control, 14(6), pp. 555-561. https://doi.org/10.1080/09537280310001613722

Yang, P. C., Wee, H. M. (2002) "The economic lot size of the integrated vendor-buyer inventory system derived without derivatives", Optimal Control Applications and Methods, 23(3), pp. 163-169. https://doi.org/10.1002/oca.706

Zailani, S., Jeyaraman, K., Vengadasan, G., Premkumar, R. (2012) "Sustainable supply chain management (SSCM) in Malaysia: A survey", International Journal of Production Economics, 140(1), pp. 330-340.

https://doi.org/10.1016/j.ijpe.2012.02.008

Zhu, Q., Sarkis, J. (2004) "Relationships between operational practices and performance among early adopters of green supply chain management practices in Chinese manufacturing enterprises", Journal of Operations Management, 22(3), pp. 265-289. https://doi.org/10.1016/j.jom.2004.01.005 